\title{
ANÁLISE DA TRAFEGABILIDADE EM ESTRADAS FLORESTAIS UTILIZANDO MÉTODOS COMPUTACIONAIS ${ }^{1}$
}

\author{
Robson Jose de Oliveira ${ }^{2}$, José Marinaldo Gleriani ${ }^{3}$, Carlos Cardoso Machado ${ }^{3}$, Reginaldo Sérgio \\ Pereira $^{4}$ e Sidney Araújo Cordeiro ${ }^{2}$
}

\begin{abstract}
RESUMO - As estradas florestais são o principal meio de integração entre as florestas e as empresas. A partir do exposto, percebe-se a necessidade não apenas da correta aplicação de atividades de manutenção, mas também de se determinar o tempo exato para tal intervenção. Partindo desse pressuposto, este trabalho apresenta os resultados da apreciação de dois métodos de classificação da qualidade de estradas não pavimentadas, com o intuito de se verificar a aplicabilidade dos mesmos na caracterização das estradas florestais brasileiras e servir como base para um sistema de gestão das operações de manutenção destas vias. Foram medidos os principais defeitos em estradas florestais seguindo um método denominado de Índice de Condição de Rodovia Não Pavimentada (ICRNP), que serviram de base para gerar um banco de dados para testar a eficiência do uso de redes neurais artificiais (RNA) na administração das estradas florestais, minimizando custos e paralisações de tráfego. Concluiu-se que a utilização das redes neurais artificiais apresentou resultados superiores ao método do ICRNP.
\end{abstract}

Palavras-chave: Estradas não pavimentadas, Transporte florestal, Redes neurais artificiais.

\section{ANALYSIS OF THE TRAFFIC PERFORMANCE IN FOREST ROADS USING COMPUTATIONAL METHODS}

\begin{abstract}
The forest roads are the main integration mode between forests and companies. Therefore, there is a need for defining not only the required maintenance activities, but also the exact time for such intervention. Starting from this premise this paper presents the results of the assessment of two methods of classification of the quality of unpaved roads in order to verify which one reflects the field reality and thus can serve as the basis for a unpaved road management system. In this paper main defects in forest roads were measured following a method named Unsurfaced Road Condition Index (URCI) which served as a database for testing the efficiency of using artificial neural networks (ANN) in the management of forest roads taking into account costs minimization and traffic stoppage. It was concluded that the use of artificial neural networks showed superior performance that the URCI method.
\end{abstract}

Keywords: Unpaved road, Forest transportation, Artificial neural networks.

\section{INTRODUÇÃO}

A enorme e crescente participação da malha rodoviária brasileira no contexto político, econômico e social está diretamente associada ao fato de o transporte ser reconhecido como fator estratégico para o desenvolvimento econômico e social de qualquer país.
Sabe-se que, entre as várias modalidades, o transporte rodoviário é a que apresenta o menor investimento de capital na aquisição da frota, sendo, por isso, o mais utilizado no Brasil. Esse predomínio se deve, entre outros, aos baixos preços praticados e à precariedade na qual se encontra e, também, a subutilização do potencial navegável dos rios (MACHADO; MALINOVSKI, 1986).

\footnotetext{
${ }^{1}$ Recebido em 11.12.2010 aceito para publicação em 05.04.2013.

${ }^{2}$ Departamento de Engenharia Florestal, Universidade Federal do Piauí, UFPI, Brasil. E-mail : <robson_ufpi@yahoo.com.br> e <Sidney.cordeiro@ufpi.edu.br $>$

${ }_{3}^{3}$ Departamento de Engenharia Florestal, Universidade Federal de Viçosa, UFV, Brasil.E-mail : <gleriani@ufv.br $>$ e $<$ machado@ufv.br $>$

${ }^{4}$ Departamento de Engenharia Florestal, Universidade Federal de Brasilia, UNb, Brasil. E-mail : <reginaldosp@ unb.br>
} 
No ano 2003, o setor florestal representou em torno de $4 \%$ do PIB, apresentando grande potencial de crescimento cada vez mais atuante na economia do nosso país, e isso se deve ao fato de que as empresas de base florestal estão cada vez mais ampliando suas capacidades instaladas, tanto para atender às necessidades do mercado quanto para a compra de novas áreas para plantios de florestas e aquisição de máquinas e equipamentos mais eficientes, buscando sempre a otimização do processo produtivo, desde o plantio e manutenção até a colheita e transporte florestal, com o intuito de reduzir os gastos com transportes, principalmente no que se refere a estradas em péssimas condições de tráfego (NOCE et al., 2005).

O termo transporte florestal se refere a toda movimentação de madeira dos talhões onde se encontram as florestas, ou das margens das estradas até o pátio das empresas, e no Brasil esse transporte representa $85 \%$ de toda madeira transportada. Mesmo com as condições deficientes dessas estradas, são elas as responsáveis pela ligação entre as comunidades produtoras e as grandes rodovias pavimentadas ou entre as florestas das empresas e as indústrias de beneficiamento da madeira. Por esse motivo, estudos buscando identificar os principais problemas e como resolvê-los são muito importantes para o transporte rodoviário florestal (SILVA et al., 2007).

Mesmo apresentando grande importância econômica e social, no Brasil há poucos relatos sobre vias não pavimentadas, o que leva à necessidade do desenvolvimento de pesquisas, visando encontrar alternativas que auxiliem na sua manutenção e reabilitação com o emprego racional dos recursos técnicos e financeiros disponíveis (OLIVEIRA et al., 2007).

Na classificação das condições da superfície estradal, podem-se empregar métodos objetivos e subjetivos. Por trabalharem de acordo com índices de condições da superfície de rolamento, os métodos objetivos alcançaram uma aceitação maior por parte dos órgãos gestores, o que levou ao seu emprego neste trabalho, para depois usar o conjunto de medições feitas dos defeitos encontrados (OLIVEIRA, 2008).

Existem vários métodos de avaliação de defeitos em estradas, e entre eles o método proposto por Eaton et al. (1987) envolve um método objetivo para o cálculo do índice de condição de rodovias não pavimentadas (ICRNP), o que se baseia em valores de dedução obtidos de acordo com os defeitos encontrados e os respectivos níveis de severidade do trecho estudado. Os defeitos são classificados de acordo com suas dimensões em relação à área do trecho em que ocorrem, e, assim, as estradas são classificadas em razão dos valores médios dos ICRNP, indicando a integridade da rodovia e obedecendo a uma escala numérica que apresenta valores variando de 0 a 100 , em que valores de 0 a 10 representam um estado péssimo de conservação do trecho em questão; de 10 a 25 , muito pobre; de 25 a 40, pobre; de 40 a 55, regular; de 55 a 70, bom; de 70 a 85, muito bom; e acima de 85 , excelente, ou seja, uma pista em perfeitas condições de trafegabilidade. Como não se calcula o defeito excesso de poeira, não há gráfico de valor dedutível para a sua densidade.

Entre as várias ferramentas computacionais que podem ser utilizadas para gerenciamento de estradas, neste trabalho utilizou-se a ferramenta Stuttgart Neural Network Simulator (SNNS), que vem sendo desenvolvida pelo Institut für Parallele und Verteilte Höchstleistungsrechner (IPVR), na Universidade de Stuttgart, desde 1989, e essas redes, chamadas de redes neurais artificiais, são técnicas computacionais que apresentam um modelo matemático inspirado na estrutura neural de organismos inteligentes e que adquirem conhecimento através da experiência. Uma grande rede neural artificial pode ter centenas ou milhares de unidades de processamento, e o cérebro de um mamífero pode ter muitos bilhões de neurônios; portanto, conclui-se que as RNAs são processadores paralelos e distribuídos massivamente, apresentando propensão natural para armazenar conhecimento proveniente da experiência, dando-lhe utilidade (HAYKIN, 2001).

\section{MATERIAL E METODOS}

\subsection{Coleta de dados}

Primeiramente, foram coletados dados sobre a quantidade e severidade de sete defeitos (seção transversal imprópria, drenagem lateral inadequada, corrugação, excesso de poeira, buracos, trilha de roda e perda de agregados), em duas empresas florestais denominadas empresas A e B, que foram analisados pelo método objetivo, denominado ICRNP, que, por ser o mais aplicado na avaliação dos defeitos mais importantes de uma via não pavimentada, levou à sua escolha neste trabalho. Depois de medidos os defeitos em unidades amostrais de $50 \mathrm{~m}$ de trechos de estradas 
florestais, usou-se o programa SNNS com base em redes neurais artificiais para gerência do pavimento florestal.

\subsection{Método objetivo ICRNP}

A determinação pelo método ICRNP é feita com base em números que oscilam de 0 até 100 , em que 100 indica que o problema presente não tem impacto na rodovia, e 0 (zero) seria um número máximo em que o defeito em questão já comprometeu toda a rodovia ou o trecho estudado.

Para se calcular esse índice, foram seguidos os seguintes passos:

$\%$ Para cada defeito separado, calculou-se a densidade de cada um deles, exceto para o defeito excesso de poeira.

Densidade $=\frac{\text { quantidade de defeitos } \mathrm{x} \mathrm{k} \mathrm{x} 100}{\text { área da unidade }\left(\mathrm{m}^{2}\right)}$

em que k é um coeficiente para correção de unidades métricas, que varia de acordo com o defeito apresentado na estrada.

Com o valor dedução total e o valor “q”, encontrouse o índice de condição de rodovia não pavimentada (ICRNP).

\subsection{A Ferramenta SNNS}

Com a utilização da ferramenta SNNS para o processamento de RNA, que possui grandes facilidades no que tange a simulação, visualização e também implementação das redes, foi possível desenvolver um sistema de gestão de pavimentos de estradas florestais, definindo-se o momento necessário para entrar com a manutenção da estrada ou de uma unidade que estiver em pior estado de conservação. Nessa ferramenta, o processo de automatização de treinamento também é característica positiva. Na Figura 1, apresenta-se um exemplo de dados de entrada no programa SNNS (HAYKIN, 2001).

Após a coleta de dados de defeitos em estradas florestais, foi elaborada uma hierarquia de importância dos principais defeitos, para que se pudesse utilizar adequadamente a ferramenta SNNS, cujo emprego demanda atribuir pesos ou graus de importância a cada parâmetro que se quer analisar.

Com a definição de uma hierarquia dos defeitos encontrados, chega-se a um modelo matemático que

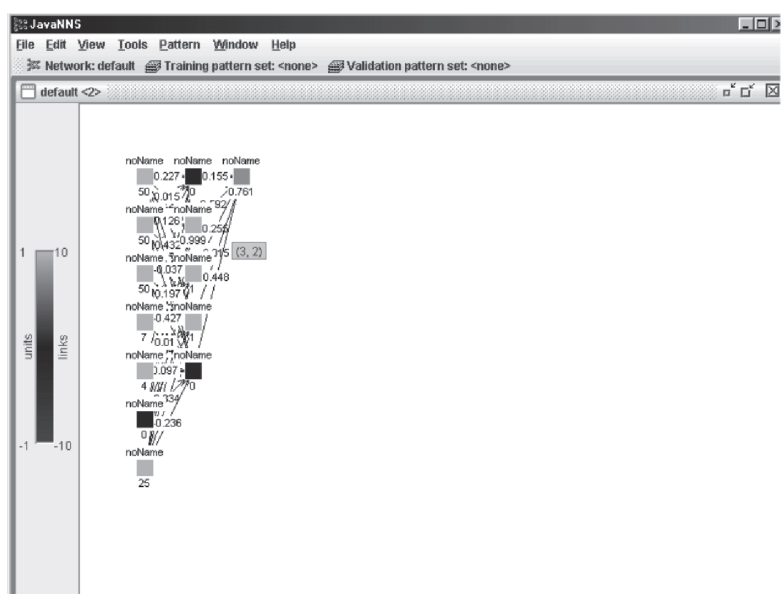

Figura 1 - Interface ilustrando os dados de entrada no programa SNNS.

Figure 1-Interface illustrating the access data in the program SNNS.

representa o grau de importância de cada problema. Com isso, têm-se os dados de entrada para o programa SNNS, que são as medidas dos defeitos no campo, e os dados de saída, que são os pesos; com cada porcentagem de cada defeito multiplicado pela quantidade do problema encontrado em cada unidade amostral, entra-se no programa SNNS para alcançar eficiência e alta flexibilidade no projeto e aplicação de redes neurais, de forma integrada em um só ambiente de simulação. A ferramenta está disponível para diversas plataformas de software e hardware, desde estações SUN rodando SunOS até PCs com sistema Linux e Windows, e permite gerenciar a implementação de uma rede neural através de um painel principal chamado de SNNS Manager, até o resultado final. Esse painel possibilita o acesso a todas as funcionalidades disponíveis no SNNS. Embora sua interface seja gráfica e de fácil utilização, um conhecimento básico de redes neurais é recomendado, pois a terminologia contida na ferramenta é altamente técnica (HAYKIN, 2001).

\section{RESULTADOS}

As Figuras 2 e 3 ilustram os resultados das metodologias utilizadas na avaliação das unidades amostrais de dados coletados nas empresas florestais A e B.

Nas Figuras 4 e 5 são apresentados os resultados das metodologias utilizadas na avaliação das unidades amostrais nas duas empresas florestais A e B, comparando-se separadamente os resultados.

Revista Árvore, Viçosa-MG, v.37, n.2, p.355-360, 2013 


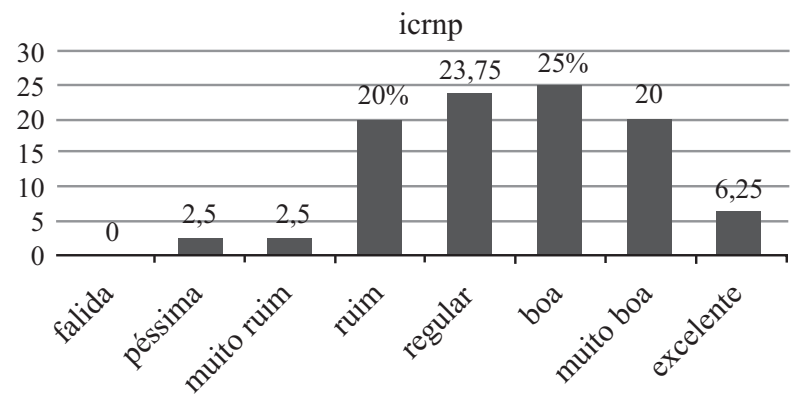

Figura 2 - Classificação das estradas pelo método ICRNP. Figure 2-Classification of the highways by the method ICRNP.

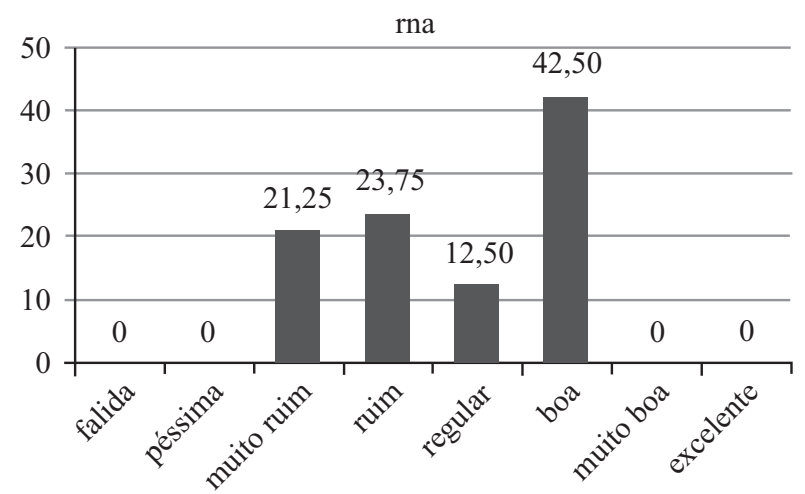

Figura 3 - Classificação das estradas pelo método RNA. Figure 3-Classification of the highways by the method RNA.

\section{DISCUSSÃO}

Como ilustrado na Figura 2, ao se empregar o método ICRNP foram encontrados $20 \%$ de unidades em estado muito bom e $23,75 \%$ em estado regular de conservação. Utilizando o software com base em Redes Neurais Artificiais (RNAs), na Figura 3 são apresentados os resultados mais confiáveis e precisos do que aqueles obtidos com o método analisado anteriormente, com $0 \%$ das unidades em estado muito bom e $12,50 \%$ em estado regular de manutenção, o que indica a necessidade de manutenção mais urgente. $\mathrm{O}$ fato de haver muitas unidades de estradas classificadas como em estado regular também ocorre em razão de a empresa, antes de entrar com as máquinas para realizar o carregamento e os caminhões para o transporte de madeira, proceder-se a uma manutenção geral na estrada e, depois, entrar com o transporte. Mas, em razão de se ter fluxo elevado e direto de caminhões pesados do tipo rodotrem e tritrem mais ônibus de transporte de trabalhadores e passageiros da comunidade que vive em torno das áreas das empresas e veículos de fazendeiros, as vias vão se deteriorando mais rapidamente nessas unidades onde foi realizada, recentemente, a manutenção do que nas outras com menos tráfego.

Foi encontrada unidade com graves problemas no eixo da estrada, sendo classificada como péssima pelo método do ICRNP e muito pobre, utilizando-se as redes neurais. Nessa unidade, quase intrafegável, foram encontrados defeitos graves de drenagem, seção transversal, poeira, buracos e trilhas de roda. Mas, em contrapartida, havia unidades com poucos problemas, detectando-se apenas poeira e, mesmo assim, em níveis baixos de severidade, indicando que não se precisa de intervenção tão rápida, sendo classificada-como excelente pelo método do ICRNP e boa pelas redes neurais. Comparando esses dois métodos, notou-se também maior rigor no resultado referente à metodologia das redes neurais, em relação ao método do ICRNP, devido ao fato de terem sido encontradas unidades amostrais classificadas como excelentes quando avaliadas pelo método ICRNP. Nas mesmas unidades avaliadas pelas RNAs, detectou-se $0 \%$ de unidades em excelente estado de conservação.

Outra constatação de interesse foi que em uma unidade foram detectados problemas, como seção transversal e drenagem ineficiente em nível médio, bem como a presença de buracos e trilha de roda em nível alto de severidade. Comparando com outras unidades em que foram encontrados apenas poeira e buracos e com base na avaliação pelas redes neurais, notou-se a importância dos defeitos de maiores pesos citados (seção transversal e drenagem ineficientes), resultando em mudança no índice de classificação da estrada de 0,4316 (classificação péssima) para 0,8700 (classificação boa).

Finalizando, ao comparar o melhor e o pior resultado de classificação das vias pelos dois métodos empregados para o ICRNP, tiveram-se os valores 98 e 2 e, para as redes neurais, 0,8950 e 0,4005 , respectivamente.

\section{CONCLUSÃO}

O método de previsão de defeitos em estradas florestais denominado ICRNP demonstrou ser técnica de interesse para avaliar e diagnosticar os principais problemas encontrados nas estradas florestais. No entanto, o uso de RNAs conduziu a resultados mais precisos e confiáveis ao comparar as Figuras 2 e 3, 


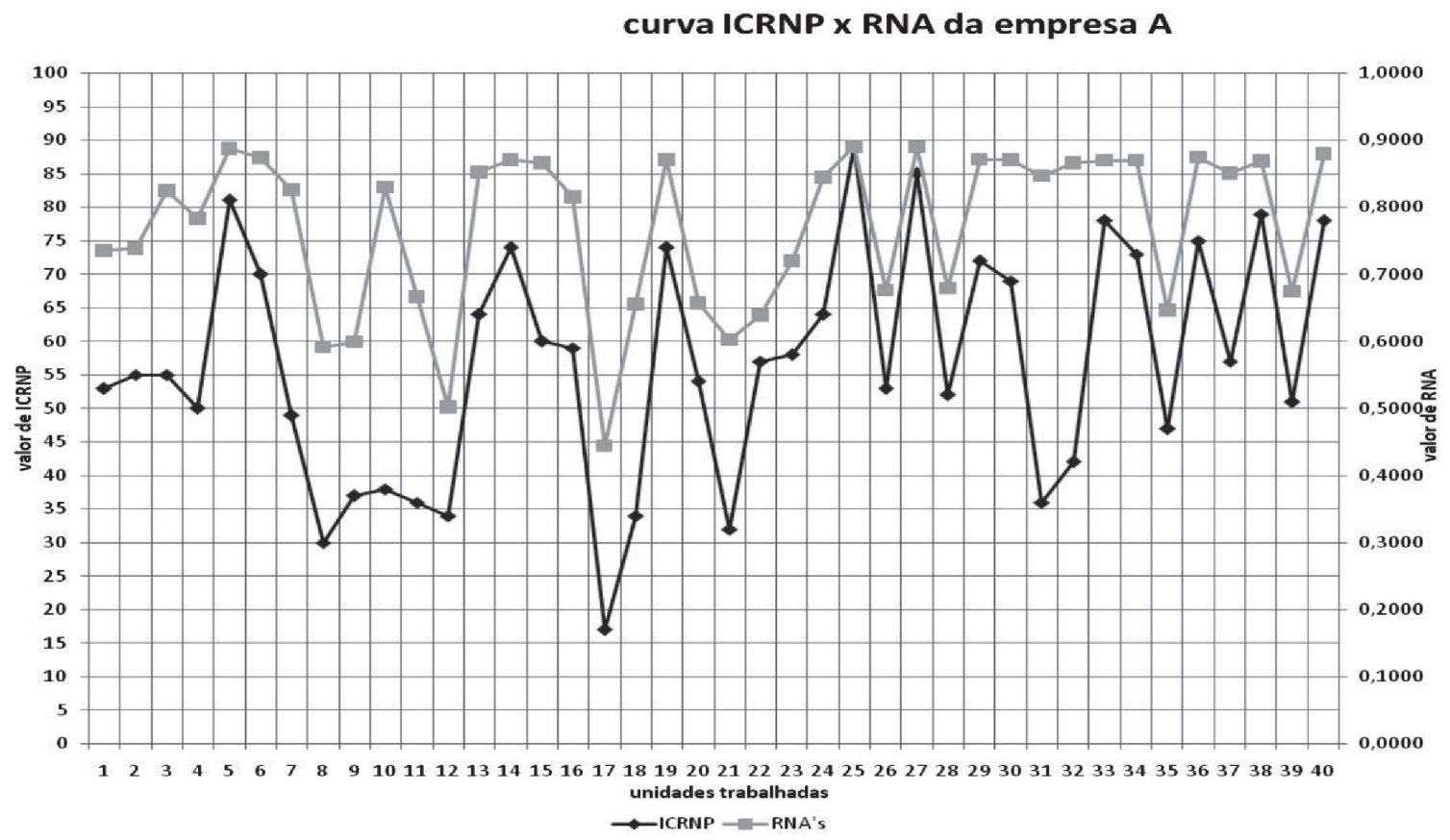

Figura 4 - Comportamento das curvas ICRNP X RNA (Empresa A).

Figure 4-Behavior of curves ICRNP X RNA (Company A).

curva ICRNP x RNA da empresa B

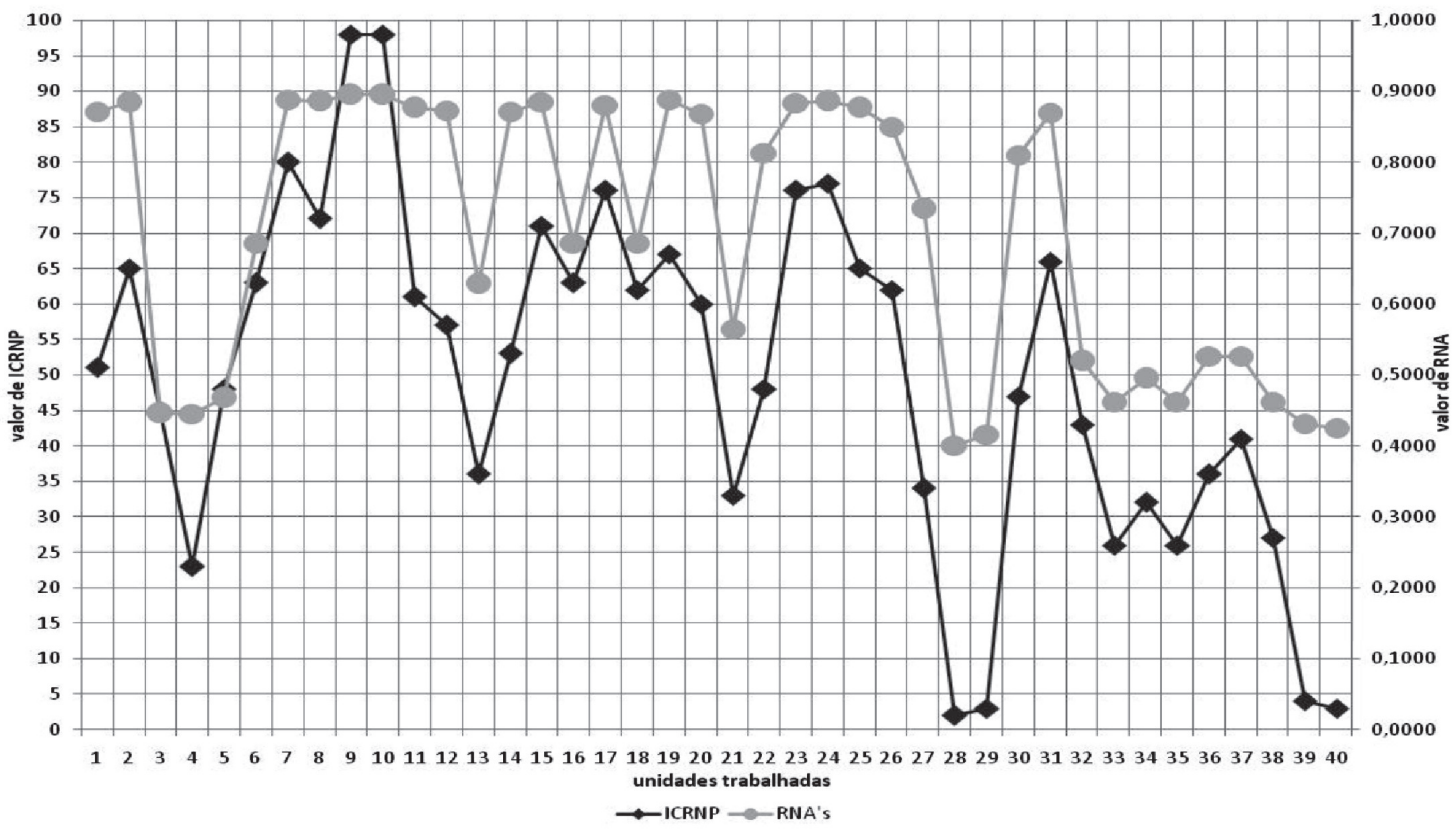

Figura 5 - Comportamento das curvas ICRNP X RNA (Empresa B).

Figure 5 - Behavior of curves ICRNP X RNA (Company B). 
em que não foram encontradas unidades amostrais classificadas como excelentes.

O processo de automatização de treinamento utilizando as RNAs foi característica positiva desse método. Não foram explorados todos os recursos dessa ferramenta no andamento do experimento, pois o trabalho era exploratório. Entretanto, a facilidade de uso, compreensão e suporte para diversas plataformas de hardware e software faz dessa ferramenta ótima candidata para ser utilizada como instrumento de didática em disciplinas introdutórias de redes neurais artificiais e programas de manutenção de estradas.

\section{REFERÊNCIAS}

EATON, R. A.; GERARD, S.; CATE, D. W. Rating unsurfaced roads - a field manual of measuring maintenance problems. Special Report. U. S. Army Corps of Engineers. Cold Regions Research \& Engineering Laboratory, 1987.p.87-115.

HAYKIN, S. Redes Neurais: princípios e práticas. 2.ed. Porto Alegre: Bookman, 2001. 900p.
MACHADO, C. C.; MALINOVSKI, J. R. Rede viária florestal. Curitiba: UFPr, FUPEF, 1986. $157 \mathrm{p}$.

NOCE, R. et al. Concentração das exportações no mercado internacional de madeira serrada. Revista Árvore, v.29, n.3, p.431-437, 2005.

OLIVEIRA, R. J. Gestão de pavimentos de estradas florestais com base em redes neurais artificiais. 2008. 105f. Tese (Doutorado) - Universidade Federal de Viçosa, Viçosa, MG, 2008.

OLIVEIRA, R. J. et al. Metodologias de previsão de defeitos em estradas florestais e levantamento da malha florestal. In: SIMPÓSIO BRASILEIRO SOBRE COLHEITAE TRANSPORTE FLORESTAL, 8., 2007, Uberlândia-MG. Anais... Uberlândia: 2007. p.393-409.

SILVA, M. L. et al. Analise do custo e do raio econômico de transporte de madeira de reflorestamentos para diferentes tipos de veículos. Revista Árvore, v.31, n.6, p.1073-1080, 2007. 